\title{
Prevalence, Aetiology, Maternal and Neonatal Outcome of Term Mothers with Anaemia, Presenting to a Tertiary Care Unit for Confinement in Sri Lanka
}

\author{
Iresh Chaminda Kandauda', Sachini Lakmini Manatunga1, Kalana Maduwage ${ }^{2}$, \\ Pushpa Manel Rathnayake ${ }^{3}$, Sampath Tennakoon ${ }^{4}$, Chiran Thejana Gunathilake ${ }^{1}$ \\ ${ }^{1}$ Department of Obstetrics and Gynaecology, Faculty of Medicine, University of Peradeniya, Peradeniya, Sri Lanka \\ ${ }^{2}$ Department of Biochemistry, Faculty of Medicine, University of Peradeniya, Peradeniya, Sri Lanka \\ ${ }^{3}$ Department of Pathology, Faculty of Medicine, University of Peradeniya, Peradeniya, Sri Lanka \\ ${ }^{4}$ Department of Community Medicine, Faculty of Medicine, University of Peradeniya, Peradeniya, Sri Lanka \\ Email: chamindakandaudagynobs@gmail.com, sachini.manatunga@gmail.com,kalanapm@gmail.com, \\ manelratnayake125@gmail.com,sampathte@yahoo.com,chamindakandaudagynobs@gmail.com
}

How to cite this paper: Kandauda, I.C., Manatunga, S.L., Maduwage, K., Rathnayake, P.M., Tennakoon, S. and Gunathilake, C.T. (2020) Prevalence, Aetiology, Maternal and Neonatal Outcome of Term Mothers with Anaemia, Presenting to a Tertiary Care Unit for Confinement in Sri Lanka. Advances in Reproductive Sciences, 8, 221-233. https://doi.org/10.4236/arsci.2020.84019

Received: October 2, 2020

Accepted: November 9, 2020

Published: November 12, 2020

Copyright $\odot 2020$ by author(s) and Scientific Research Publishing Inc. This work is licensed under the Creative Commons Attribution International License (CC BY 4.0).

http://creativecommons.org/licenses/by/4.0/

\begin{abstract}
Objective: To describe the proportion of women presenting with undiagnosed anaemia at confinement and to explore associations between anaemia and socio economic factors, dietary pattern and compare maternal and neonatal outcome among term mothers with anaemia compared to non-anaemic pregnant women at a tertiary care centre in Sri Lanka. Method: A comparative cross-sectional study was performed by recruiting anaemic and non-anaemic term mothers who delivered at the Teaching Hospital Peradeniya during the period March 2018-March 2019. Pregnant mothers whose haemoglobin level was less than $10.5 \mathrm{~g} / \mathrm{dl}$ were considered as anaemic and compared with the mothers whose haemoglobin level was above this level. With written consent, demographic data, etiological factors, maternal and neonatal outcomes of term mothers were evaluated by an interview and blood samples were withdrawn to carry out anaemia related investigations. Results: Among 2854 pregnancies, a total of 234 (8.19\%) term pregnant mothers were anaemic and they were and compared with 199 non-anaemic mothers. Out of the anaemic mothers $(\mathrm{Hb}<105 \mathrm{~g} / \mathrm{l}), 133(56.76 \%)$ had moderate anaemia, $100(42.79 \%)$ had mild anaemia and 1 mother $(0.45 \%)$ had severe anaemia. Low monthly family income was significantly associated with the incidence of anaemia. Anaemia was also associated with low weekly consumption of red meat (OR 8.994; 95\% CI, $5.74-14.09, \mathrm{p}<0.05)$ and high weekly tea intake (OR 0.217;
\end{abstract}


95\% CI $0.144-0.327, \mathrm{p}<0.05)$. Among anaemic mothers, $215(67.44 \%)$ had low serum ferritin $(<30 \mathrm{ng} / \mathrm{mL})$ while most of them were diagnosed with iron deficiency anaemia $(58.24 \%)(n=113)$ based on haemoglobin. Most anaemic mothers had undergone elective caesarean section (46.26\%) while vaginal deliveries $(33.33 \%)$ were common among non-anamic group. Conclusions: A moderate prevalence of anaemia among term pregnant women in Peradeniya, Sri Lanka was observed and was associated with low socio economic status, low consumption of tea and poor nutrition lacking in red meat.

\section{Keywords}

Term Mothers, Prevalence, Anaemia, Maternal Outcome, Neonatal Outcome

\section{Introduction}

Anaemia in pregnancy is a long known major health problem in developed and developing countries. Prevalence of anaemia in pregnancy varies from $15 \%$ in developed countries [1] and 33\% to $75 \%$ in developing countries [2]. World health organization (WHO) defines a haemoglobin concentration of $110 \mathrm{~g} / \mathrm{l}$ as the cut off level to diagnose anaemic during pregnancy. It is subcategorized as mild (10.0 - $10.9 \mathrm{~g} / \mathrm{dl})$, moderate $(7.0-9.9 \mathrm{~g} / \mathrm{dl})$ and severe $(<7.0 \mathrm{~g} / \mathrm{dl})$ anaemia [3]. According to the UK guidelines for haematology and the RCOG NICE guidelines, anaemia in pregnancy is defined as haemoglobin concentration $(\mathrm{Hb})$ $<110 \mathrm{~g} / \mathrm{l}$ in first trimester and $<105 \mathrm{~g} / \mathrm{l}$ in second and third trimesters and $<100$ g/l immediately postpartum [4] [5]. Sri Lankan college of haematologists recommends the cut of values given by the UK guidelines and it is currently used in Sri Lanka to diagnose anaemia in pregnancy.

During the period of pregnancy, blood plasma volume begins to increase physiologically at the beginning of the first semester and plateaus in the third semester. This occurs at a higher rate than the red blood cell and haemoglobin production, which causes a haemodilution effect and the resulting condition is referred to as physiological anaemia [4]. Hence, during the second and third trimesters of pregnancy, $\mathrm{Hb}<105 \mathrm{~g} / \mathrm{l}$ is considered as anaemia while a normal person is diagnosed as anaemic when the $\mathrm{Hb}<110 \mathrm{~g} / \mathrm{l}$. Due to the haemodilution effect, the risk of developing anaemia is higher during pregnancy. It is associated with adverse maternal outcomes, such as puerperal sepsis, antepartum haemorrhage, postpartum haemorrhage, and more [6]. Apart from maternal risks, it is also responsible for premature delivery, low birth weight babies and high perinatal mortality [7]. The causes of anaemia in pregnancy are Folate and vitamin B12 deficiency, inflammatory disorders, thalassemia, haemolysis and blood loss and the most common nutritionally related iron deficiency anaemia [4]. There is a huge demand for iron during the period of pregnancy as the frequency of maternal erythropoiesis is high due to increased plasma volume and the utilization of iron for the fetal growth. Iron-deficiency anaemia occurs when 
there is shortage of iron stores, transport and functional iron, resulting in reduced haemoglobim in addition to low serum ferritin, low transferrin saturation and increased erythrocyte protoporphyrin concentration [4]. Beside poor nutrition, late booking, low financial status, multiparity, abortion, frequent pregnancies, infections, consuming excess tea or coffee after meals determined as the predictors of anaemia in pregnancy [8].

Due to high prevalence and known complications of anaemia in pregnancy, every mother is checked for anaemia at booking visit, at 28 weeks of gestation and on admission for confinement in most of the countries. The Sri Lankan maternal health programme contains several strategies to prevent anaemia during pregnancy. They are oral iron, vitamin $\mathrm{C}$, folate and food supplementations provided at antenatal clinics for every pregnant woman free of charge.

In Sri Lanka, where there are wide variations in socioeconomic status, dietary patterns and different cultural taboos, the prevalence of anaemia could vary in different geographical areas. WHO estimated that prevalence of pregnancy associated anaemia is around 29\% in Sri Lanka [9]. In 2007, a demographic and health survey (DHS) reported an overall prevalence of $34 \%$ with $20.7 \%$ mild and $13.3 \%$ moderate to severe anaemia [10]. In 2009, there was a survey, which showed $17 \%$ prevalence of anaemia during pregnancy in Sri Lanka, with $7 \%$ in Kurunegala district to $29 \%$ in Colombo district [11].

Although several studies had been conducted to identify the prevalence of anaemia among pregnant women in Sri Lanka, there are only few reports available on the prevalence of anaemia among term pregnant mothers. A survey study conducted in Anuradhapura district in 2012 had found that the prevalence of anaemia in first, second and third trimesters was 7.6\%, 19.7\%, and 19.3\% respectively [12]. Even though several studies show a wide range of prevalence, all these show lower estimations than WHO records. A reliable estimate of the prevalence of anaemia in Sri Lanka is needed as it will enable a proper evaluation of the public health of the country. Hence, the present study was conducted to describe the prevalence of anaemia among term mothers in Peradeniya, Sri Lanka and to describe the aetiology, socio economic factors, and dietary pattern and maternal and neonatal outcomes among term mothers with anaemia.

\section{Materials and Methods}

This comparative cross sectional study was conducted between March 2018 to March 2019 on term pregnant anaemic mothers and term pregnant non anaemic mothers presenting to the antenatal ward for confinement at Teaching Hospital Peradeniya, Sri Lanka.

The minimum required sample size was 239 for each group calculating for a prevelance of low birth weight of $12.5 \%$ at precision of 0.05 and a confidence level of $90 \%$ (lwanga and lemeshow). Inclusion criteria for the anaemic group was defined as follows; pregnant women between 18 - 40 years, term mothers (37 weeks to 42 weeks of gestation) with a haemoglobin $(\mathrm{Hb})$ level less than 10.5 
$\mathrm{g} / \mathrm{dl}$ on admission for confinement. Women with chronic cardiac diseases, renal diseases and foetuses with congenital anomalies were excluded. All anemic women who met inclusion and exclusion criteria were invited to take part in the study until the required sample size was achieved. The non-anemic group was selected through a systematic sampling method to spread the sample throughout the study period. Selected women were evaluated in detail regarding their diet. Haemoglobin concentration, red blood cell indices, erythrocyte sedimentation rate and the blood picture were performed under the supervision of a consultant haematologist, Teaching Hospital Peradeniya. Due to the unavailability of the serum ferritin assay in the hospital laboratory, ferritin assay was done at the biochemistry laboratory, Lanka Hospital, Kandy. Samples were analyzed using electrochemiluminescence immunoassay (ECLIA) using Cobas e 411 fully automated immunoassay analyzer.

Mode of delivery, number of blood transfusions, booking, and postpartum haemoglobin concentration, red blood incident, haematocrit (HCT), mean corpuscular haemoglobin $(\mathrm{MCH})$, mean corpuscular volume (MCV) were recorded to relate the maternal outcome to the severity of anamia. The neonatal outcomes were assessed by 5 min and 10 min Apgar scores, birth weight, cord blood haemoglobin, and red blood incident. Cord blood samples were collected at the time of delivery and sent for full blood count. WHO criteria were used as cut off values for ferritin $(<30 \mathrm{ng} / \mathrm{mL})$. Cut off levels of $<13.6 \mathrm{~g} / \mathrm{dl}$ for cord blood haemoglobin and $<10.0 \mathrm{~g} / \mathrm{dl}$ for postpartum haemoglobin were used. Corrected reticulocyte count was calculated using reticulocyte $\% \mathrm{X}$ (patient haematocrit/normal haematocrit).

The data were collected and analyzed using the Statistical Package of social science (SPSS) version 13.0 for windows. Results were reported in the form of simple frequency and mean and standard deviation (SD). Categorical variables were compared using the Chi-square test and Independent sample $t$ test was used to compare quantitative variables between anaemic and non-anaemic mothers. A $\mathrm{p}$ value of $<0.05$ was considered statistically significant. Monthly income and dietary habits were included in the regression model as dichotomous variables. The results were presented in odd ratios (OR) and $95 \%$ confidence intervals.

The study protocol was approved by the ethical committee Faculty of Medicine, University of Peradeniya (2017/EC/42), Sri Lanka. Informed written consent was obtained from each participant after explaining the study procedure. An information sheet was provided in all three official languages (Sinhala, Tamil, English) as to include all ethnic groups. Participants had a chance to clarify their doubts and only those consented for the research had been included in the study. The confidentiality of the research data was well maintained. The benefits from this study to the health sector and to the society were explained.

\section{Results}

Out of total 2854 pregnant women admitted for confinement, 234 term women 
were found to be anaemic as their haemoglobin level was less than $105 \mathrm{~g} / \mathrm{l}$. They were compared with 199 term non anaemic women. The median age of anaemic women was $28.66 \pm 5.73$ years and in non anaemic group, it was $28.80 \pm 5.35$ years. $(\mathrm{p}=0.08)$. Out of 234 anaemic women, the majority $126(56.76 \%)$, had moderate anaemia (Hb 9.9 - $7.0 \mathrm{~g} / \mathrm{dl}$ ), 95 (42.79\%) had mild anaemia (Hb 10.5 $9.9 \mathrm{~g} / \mathrm{dl})$ whereas $1(0.45 \%)$ was severe anaemic $(\mathrm{Hb}<7.0 \mathrm{~g} / \mathrm{dl})$. Majority of anaemic women were Sinhalese, 113 (50.0\%), followed by Muslims, 91 (40.27\%) and Tamil, 22 (9.9\%). Of these women, 119 (52.42\%) were between 21 - 30 years, while $89(39.65 \%)$ were 31 years or above and $18(7.92 \%)$ were 20 years or less. There was no statistically significant difference between anaemia and women's age. $(p=0.583)$ The proportion of anaemia was higher among those women whose monthly income was less than Rs. 30,000 (51.32\%). There was a significant difference between anaemic and non anaemic mothers in relation to the monthly family income (OR 3.9; 95\% CI, 2.6-6.1, p < 0.05). Among anaemic mothers, $196(83.34 \%)$ were housewives while 24 (10.57\%) were professional employees. Of the term anaemic mothers, $64(28.19 \%)$ had no dependents and 137 (60.35\%) had 1 - 3 children while with non anaemic mothers 101 (48.09\%) had no dependents and $97(43.30 \%)$ had $1-3$ children $(\mathrm{p}<0.05)$ (Table 1). The comparison of these parameters is given in Table 1.

In analysing the dietary habits among anaemic women, 183 (81.7\%) had low consumption (less than 4 times per week) of red meat. Among non-anaemic group, $133(66.8 \%)$ had an adequate amount of red meat and only $33.2 \%$ had low consumption of red meat. Therefore, there is a significant relationship between anaemia and red meat consumption among anaemic and non anaemic women (OR, 8.994; 95\% CI, 5.74 - 14.09, p < 0.05). Mothers who consumed tea more than two times per week were considered as high tea consumers and the mother who consumed tea twice or less than that per week were considered sufficient tea intakes. Of the anaemic mothers, 158 (70.5\%) had high weekly tea intake (OR, 0.217; 95\% CI, $0.144-0.327, \mathrm{p}<0.05)$ while $29.5 \%$ had sufficient tea intake. Moreover, the percentage of tea intake was higher among $(53.79 \%)$ the women with lower income $(<$ Rs. 30,000) per month.

Serum haemoglobin level $(\mathrm{Hb})$ was available only for 222 anaemic mothers on admission. The mean value for the anaemic group for $\mathrm{Hb}$ was $9.51 \pm 0.74 \mathrm{~g} / \mathrm{dl}$ and for the non-anaemic group was $11.95 \pm 1.06 \mathrm{~g} / \mathrm{dl}$. Out of the non-anaemic group, only 182 had reports on red blood cell count (RBC), HCT, MCV, MCH, mean corpuscular haemoglobin concentration $(\mathrm{MCHC})$ and red cell distribution width coefficient of variation (RDW- CV). Except the mean RDW value, all other values were lower in anaemic women comparing with non anaemic women. As seen in Table 2 the mean Hb, HCT, and MCV were significantly lower and RDW-CV was significantly higher among anaemic and non anaemic group ( $\mathrm{p}<0.05)$. Among anaemic mothers, 221 had low HCT value $(<37 \%)$ and only one had a higher value ( $>54 \%)$. Regarding MCV 142 women had lower values $(<80 \mathrm{fL})$, four of them had higher values $(>100 \mathrm{fL})$ and the rest of them were in normal range $(80-100 \mathrm{fL})$. 
Table 1. Socio demographic characteristics.

\begin{tabular}{|c|c|c|c|c|c|}
\hline \multirow[b]{2}{*}{$\begin{array}{l}\text { Socio demographic } \\
\text { characteristics }\end{array}$} & \multicolumn{2}{|c|}{ Anaemic mothers } & \multicolumn{2}{|c|}{ Non-anaemic mothers } & \multirow[b]{2}{*}{$P$ value } \\
\hline & $\begin{array}{c}\text { No. of } \\
\text { anaemic } \\
\text { mothers }\end{array}$ & Percentage & $\begin{array}{c}\text { No. of } \\
\text { non-anaemic } \\
\text { mothers }\end{array}$ & Percentage & \\
\hline \multicolumn{6}{|l|}{ Ethnicity } \\
\hline Sinhala & 113 & $50.00 \%$ & 146 & $74.11 \%$ & \multirow{4}{*}{$<0.05$} \\
\hline Tamil & 22 & $9.73 \%$ & 3 & $1.52 \%$ & \\
\hline Muslim & 91 & $40.27 \%$ & 46 & $23.35 \%$ & \\
\hline Catholic & 0 & 0 & 2 & $1.02 \%$ & \\
\hline \multicolumn{6}{|l|}{ Age } \\
\hline 20 years & 18 & $7.93 \%$ & 12 & $6.03 \%$ & \multirow{3}{*}{0.583} \\
\hline $21-30$ years & 119 & $52.42 \%$ & 113 & $56.78 \%$ & \\
\hline 31 years & 90 & $39.65 \%$ & 74 & $37.19 \%$ & \\
\hline \multicolumn{6}{|l|}{ Women's Education } \\
\hline Up to Grade 5 & 4 & $1.76 \%$ & 1 & $0.5 \%$ & \multirow{6}{*}{$<0.05$} \\
\hline Grade 5 - Ordinary Level & 25 & $11.01 \%$ & 32 & $16.08 \%$ & \\
\hline Ordinary Level & 94 & $41.41 \%$ & 36 & $18.09 \%$ & \\
\hline Up to Advance Level & 88 & $38.77 \%$ & 107 & $55.77 \%$ & \\
\hline Undergraduate & 3 & $1.32 \%$ & 0 & $0.00 \%$ & \\
\hline Graduate & 13 & $5.73 \%$ & 23 & $11.56 \%$ & \\
\hline \multicolumn{6}{|l|}{ Women's Occupation } \\
\hline Housework & 196 & $86.34 \%$ & 154 & $77.39 \%$ & \multirow{5}{*}{$<0.05$} \\
\hline Unskilled & 1 & $0.44 \%$ & 3 & $1.51 \%$ & \\
\hline Skilled & 3 & $1.33 \%$ & 2 & $1.01 \%$ & \\
\hline Business & 3 & $1.33 \%$ & 39 & $19.60 \%$ & \\
\hline Professional & 24 & $10.57 \%$ & 1 & $0.50 \%$ & \\
\hline \multicolumn{6}{|l|}{ Husband's Education } \\
\hline No school attendance & 1 & $0.44 \%$ & 2 & $1.01 \%$ & \\
\hline up to Grade 5 & 2 & $0.88 \%$ & 0 & $0.00 \%$ & \\
\hline Grade 5 - Ordinary Level & 41 & $18.06 \%$ & 45 & $22.61 \%$ & \\
\hline Ordinary Level & 96 & $42.29 \%$ & 39 & $19.60 \%$ & $<0.05$ \\
\hline Up to Advance Level & 76 & $33.48 \%$ & 102 & $51.26 \%$ & \\
\hline Undergraduate & 1 & $0.44 \%$ & 0 & $0.00 \%$ & \\
\hline Graduate & 10 & $4.41 \%$ & 10 & $5.03 \%$ & \\
\hline Post Graduate & 0 & $0.00 \%$ & 1 & $0.50 \%$ & \\
\hline \multicolumn{6}{|l|}{ Husband's Occupation } \\
\hline Housework & 2 & $0.88 \%$ & 2 & $1.01 \%$ & $<0.05$ \\
\hline Unskilled & 59 & $25.99 \%$ & 37 & $18.59 \%$ & \\
\hline
\end{tabular}




\section{Continued}

\begin{tabular}{cccccc}
\hline Skilled & 55 & $24.23 \%$ & 23 & $11.56 \%$ & \\
Business & 64 & $28.19 \%$ & 65 & $32.66 \%$ & \\
Professional & 47 & $20.71 \%$ & 72 & $36.18 \%$ & \\
Income & & & & & \\
$<30,000$ & 116 & $51.33 \%$ & 42 & $21.11 \%$ & $<0.05$ \\
$>30,000$ & 110 & $48.67 \%$ & 157 & $78.89 \%$ & \\
No of dependents & & & & & \\
No child & 64 & $28.19 \%$ & 101 & $48.09 \%$ & \\
1 - 3 Children & 137 & $60.35 \%$ & 97 & $43.30 \%$ & \\
4 - 7 Children & 26 & $11.45 \%$ & 26 & $11.61 \%$ & \\
\hline
\end{tabular}

Table 2. Comparison of haematological parameters among anaemic and non anaemic women on admission.

\begin{tabular}{cccccc}
\hline & Group & Mean & Std. Deviation & Std. Error Mean & P Values \\
\hline $\mathrm{Hb}$ & Anaemic & 9.516 & 0.7460 & 0.0501 & \\
& Non Anaemic & 11.954 & 1.0643 & 0.0754 & $<0.001$ \\
$\mathrm{RBC}$ count & Anaemic & 3.9339 & 0.54546 & 0.03661 & \\
& Non Anaemic & 4.5167 & 2.74154 & 0.20322 & 0.395 \\
$\mathrm{HCT}$ & Anaemic & 29.915 & 3.3257 & 0.2232 & 0.003 \\
& Non Anaemic & 37.394 & 3.3869 & 0.2511 & \\
$\mathrm{MCV}$ & Anaemic & 76.176 & 11.4126 & 0.7660 & $<0.001$ \\
& Non Anaemic & 86.572 & 8.8025 & 0.6525 & \\
$\mathrm{MCH}$ & Anaemic & 24.673 & 3.7055 & 0.2487 & 0.080 \\
& Non Anaemic & 28.186 & 5.6669 & 0.4201 & \\
$\mathrm{MCHC}$ & Anaemic & 31.964 & 1.6194 & 0.1087 & 0.159 \\
& Non Anaemic & 32.090 & 5.0554 & 0.3747 & \\
& Anaemic & 15.979 & 3.5873 & 0.2413 & 0.001 \\
$\mathrm{RDW}$ & Non Anaemic & 14.328 & 2.6141 & 0.1938 & \\
& & & & & \\
& & & &
\end{tabular}

Of the 215 subjects who had $\mathrm{Hb}$ level less than $10.5 \mathrm{~g} / \mathrm{dL}, 145$ (67.44\%) had low serum ferritin $<30 \mathrm{ng} / \mathrm{mL}$ while others were in a normal range. Based on the characteristics of the blood picture among the study population, most of them $113(58.24 \%)$ were diagnosed as iron deficiency anaemia, 5 (2.57\%) had thalassaemia trait and $46(23.71 \%)$ had both (Figure 1 ). Around $4.5 \%$ of the study population had higher $(>2.5 \%)$ corrected reticulocyte count and only $1.8 \%$ had a lower count $(<0.5 \%)$. Additionally, among the participants, $198(19.19 \%)$ had undergone at least one blood transfusion.

Of the anaemic women, 188 postpartum blood reports were compared with 98 non anaemic mothers. As observed in Table 3, there was a significant difference 


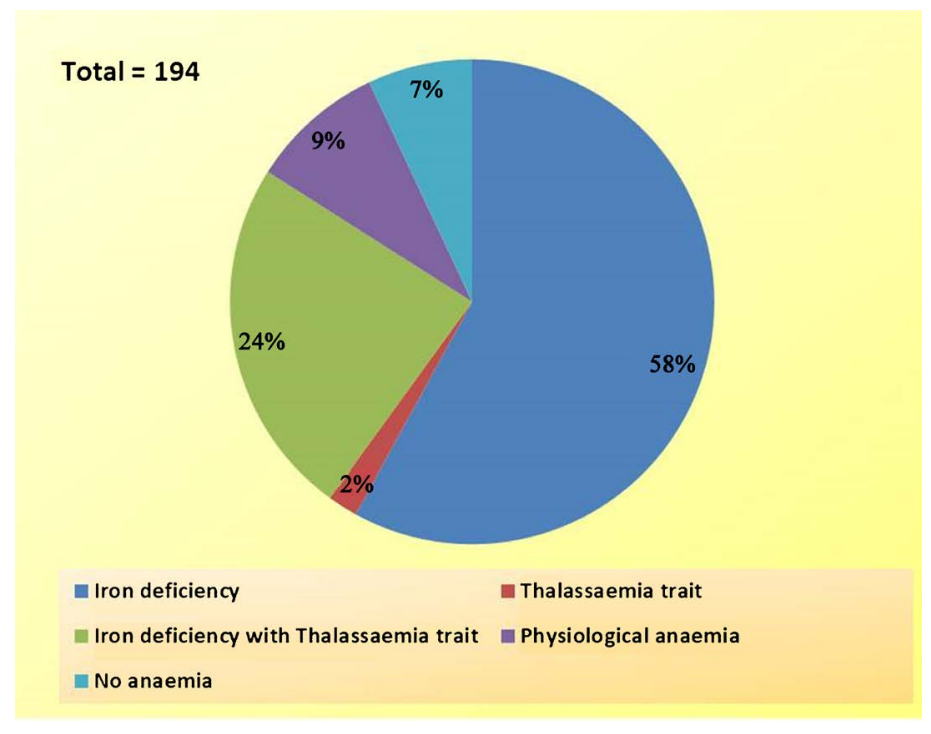

Figure 1. Haematological diagnosis based on blood picture.

Table 3. Comparison of postpartum haematological parameters among anaemic and non anaemic women.

\begin{tabular}{cccccc}
\hline & Group & Mean & Std. Deviation Std. Error Mean & P Values \\
\hline Postpartum Hb & Anaemic & 9.429 & 1.0001 & 0.0729 & 0.003 \\
& Non Anaemic & 11.331 & 1.2199 & 0.0878 & \\
Postpartum RBC & Anaemic & 4.0773 & 2.90458 & 0.21184 & 0.513 \\
& Non Anaemic & 4.1069 & 1.11052 & 0.11218 & \\
Postpartum HCT & Anaemic & 29.522 & 2.9368 & 0.2142 & \multirow{2}{*}{0.002} \\
& Non Anaemic & 34.964 & 3.8713 & 0.3911 & \\
Postpartum MCV & Anaemic & 76.756 & 10.3912 & 0.7579 & 0.087 \\
& Non Anaemic & 86.471 & 11.0262 & 1.1138 & \\
Postpartum MCH & Anaemic & 24.707 & 3.6887 & 0.2690 & $<0.001$ \\
& Non Anaemic & 28.018 & 2.8080 & 0.2836 & \\
Postpartum MCHC & Anaemic & 31.848 & 1.2780 & 0.0932 & 0.168 \\
& Non Anaemic & 31.454 & 2.2714 & 0.2294 & \\
\hline Postpartum RDW-CV & Anaemic & 16.270 & 3.2187 & 0.2347 & 0.001 \\
& Non Anaemic & 14.631 & 3.1323 & 0.3164 & \\
\hline
\end{tabular}

in postpartum $\mathrm{Hb}, \mathrm{HCT}, \mathrm{MCH}$, and $\mathrm{RDW}-\mathrm{CV}$. Out of all the haematological values, Anaemia group had lower mean values for HCT and $\mathrm{MCH}$ in comparison with the non-anaemic group. Majority around 137 (72.87\%) had low $(<10.0$ $\mathrm{g} / \mathrm{dl}$ ) postpartum haemoglobin among anaemic women.

Even though maternal postpartum $\mathrm{Hb}$ is less among anaemic women, cord blood $\mathrm{Hb}$ is normal for 54 babies $(79.41 \%)(\mathrm{n}=68)$. There were 14 babies (20.58\%) who had cord blood $\mathrm{Hb}<13.6 \mathrm{~g} / \mathrm{dl}$. Regarding the mode of delivery of baby among term anaemic mothers, most of them were undergone elective cae- 
sarean section 94 (46.26\%) followed by vaginal delivery 67 (33.33\%), emergency caesarean section 39 (19.40\%), and vacuum delivery 1 (0.99\%) respectively. Among the non-anaemic group, $61.92 \%$ have undergone vaginal delivery. Therefore, there was a significant difference in the method of delivery among anaemic and non-anaemic mothers. Nevertheless, there was no statistical difference in the birth weight of the baby $(p=0.238)$. Nevertheless, there was a significant difference in APGAR score at 5 minutes. Average APGAR score at 5 minutes, 10 minutes for anemic group was $9.67 \pm 0.48$ and $10 \pm 0.07$ whereas $10 \pm 0.00,10 \pm$ 0.00 for non-anaemic mothers. Also non had Apgar scores below seven at 5 and 10 minutes.

\section{Discussion}

Sri Lanka is one of the countries in the world that provides the highest quality of free health care despite its low economic development. Over the past few decades, it has provided optimal antenatal care in comparison to the other South Asian Countries. Though several steps were taken to prevent anaemia such as preconception care for early detection, but still there are women who present for deliveries with anaemia.

The prevalence of anaemia in this study was $8.19 \%$ among term pregnant women: it was less than the prevalence that was reported in third trimester mothers in the Anuradhapura district [12]. As we have taken only the term mothers our finding did not correlate with the result reported by WHO, DHS and with the Senadheera et al. study [5] [6]. The prevalence of anaemia in our study was lower than those reported from Tanzania (47\%) [13] and South Nigeria $30.03 \%$ [14], but was similar to the study from Iran conducted in 2009 [15].

Expectedly, as in the study from India, most of the anaemic patients in this study presented with moderate anaemia [7], whereas $0.45 \%$ were noted with severe Anaemia unlike in Nigeria where no case of severely anaemic pregnant mothers were present [16]. Socio economic status is a known factor for anaemia in pregnancy. In this study, anaemia was more prevalent among women who had low monthly family income similar to the study conducted in Turkey [8]. Anaemia was more prevalent in women with one to three living children than women with no child. However, we did not observe a homogeneous increase in anaemia with regard to the increase in maternal age. Hence, further studies are required to explain its effect on anaemia in pregnancy.

This data also highlights the fact that prevalence of anaemia was high in women with low consumption of red meat and high tea intake. It is stated in the literature that tea consumption and low intake of red meat are associated with anaemia [17] [18] [19]. Some studies reported that iron absorption is reduced by frequent tea intake [20] [21] [22] [23]. Compared to the developing countries, meat consumption is high in developed countries [24]. Major reason for this is, in developing countries there is a large fraction of people with limited means, who are unable to purchase meat to include in their meals compared with the 
wealthy in developed countries.

Even though Sri Lanka provides a good health care system, the number of maternal death caused due to haemorrhage and anaemia is high. This raises a question on the current practices used to screen anaemia during pregnancy and the quality of screening in Sri Lanka. A study done by Prathapan et al. showed that only $4 \%$ of the pregnant women in Sri Lanka were provided with information regarding the behavioural and nutritional habits that should be followed during pregnancy [25]. Therefore, education about nutrition should be developed according to the guideline for antenatal care. Findings of this research will motivate antenatal care providers toward early detection of anaemia and promote the necessary management of anaemia in pregnancy.

As in the prevalence study from Turkey [8], all haematological values were low at booking in anaemic group compared with the non-anaemic group except the mean RDW-CV value. Our study also concludes that $67.44 \%$ of anaemic women had serum ferritin $<30 \mathrm{ng} / \mathrm{mL}$. This is important because it is the most appropriate method for the diagnosis of iron deficiency anaemia. But in routine antenatal care in Sri Lanka serum ferritin is not assessed due to its high cost.

In this study, iron deficiency anaemia was predominant among anaemic pregnancies, as in Senadheera et al. study [26]. But the prevalence of iron deficiency anaemia is higher compared to the Senadheera et al. study $36.9 \%$ [26]. Hence, this study shows number of areas to be improved in pre-conceptional care specially in Iron and folic acid supplementation. Results of the study found that $20.58 \%$ had low cord blood haemoglobin. Nevertheless, it needs further investigation as the present study did not assess the cord blood $\mathrm{Hb}$ of babies delivered by non-anaemic mothers. Moreover, there was a significant difference in APGAR score at 5 minutes. Other parameters, however, did not find any association between maternal anaemia and adverse pregnancy outcome.

The major drawback of the study was regarding ferritin assay. It was carried out only for the anaemic mothers at the booking visit. Therefore, we could not compare the serum ferritin values in between anaemic and non-anaemic pregnancies. In addition, we had used only the blood picture to diagnose thalassemia, as the facility to use HPLC is not freely available in the Sri Lankan health sector. Also due to a data loss, only 234 anaemic mothers and 199 non anaemic mothers were taken for the study, even though the calculated sample size was 239 for each group.

\section{Conclusion}

In conclusion, there was a moderate prevalence of iron deficiency Anaemia in pregnant women in Peradeniya, Sri Lanka. Devastating effects of anaemia associated with pregnancy could be prevented by early registration, close antenatal follow up, early detection and treatment of anaemia with proper guideline according to the haematologist and nutritionist before delivery. All of these would help to guarantee safe motherhood and babyhood. 


\section{Acknowledgements}

The authors gratefully acknowledge the help and cooperation extended by staff members at ward 10 Teaching Hospital Peradeniya and staff at Department of Obstetrics and Gynaecology, Faculty of Medicine, University of Peradeniya. The authors also acknowledge medical laboratory technicians at Lanka Hospital laboratory, Kandy.

\section{Authors Contribution}

I.C Kandauda participated in the design of the study, performed the data collection and served as the lead author of the manuscript. S.L Manatunga performed data collection, participated in drafting the manuscript and helped to performed statistical analysis. K Maduwage participated in design of the study, helped to draft the manuscript and performed statistical analysis. P.M Rathnayake participated in design of the study and did all the haematological analysis. S. Tennakoon participated in design of the study and performed statistical analysis. All authors read and approved the final manuscript.

\section{Conflicts of Interest}

The authors declare no conflicts of interest regarding the publication of this paper.

\section{References}

[1] World Health Organization (1993) Prevention and Management of Severe Anaemia in Pregnancy: Report of a Technical Working Group. WHO, Geneva.

[2] van den Broek, N.R. and Letsky, E.A. (2000) Aetiology of Anaemia in Pregnancy in South Malawi. The American Journal of Clinical Nutrition, 72, 247S-256S. https://doi.org/10.1093/ajcn/72.1.247S

[3] World Health Organization (2011) Haemoglobin Concentrations for the Diagnosis of Anaemia and Assessment of Severity. http://www.who.int/vmnis/indicators/haemoglobin.pdf

[4] Pavord, S., Daru, J., Prasannan, N., Robinson, S., Stanworth, S., Girling, J. and British Society for Haematology Committee (2020) UK Guidelines on the Management of Iron Deficiency in Pregnancy. British Journal of Haematology, 188, 819-830. https://doi.org/10.1111/bjh.16221

[5] Royal College of Obstetricians and Gynaecologists (2015) Blood Transfusions in Obstetrics. Green-Top Guideline, Article No. 47.

[6] Roy, S. and Chakravorty, P.S. (1992) Maternal and Perinatal Outcome in Severe Anaemia. The Journal of Obstetrics and Gynecology of India, 42, 743-750.

[7] Gautam, V.P., Bansal, Y., Taneja, D.K. and Saha, R. (2002) Prevalence of Anaemia amongst Pregnant Women and Its Sociodemographic Associates in a Rural Area of Delhi. Indian Journal of Community Medicine, 27, 156-160.

[8] Karaoglu, L., Pehlivan, E., Egri, M., Deprem, C., Gunes, G., Genc, M.F. and Temel, I. (2010) The Prevalence of Nutritional Anaemia in Pregnancy in an East Anatolian Province, Turkey. BMC Public Health, 10, 329.

https://doi.org/10.1186/1471-2458-10-329 
[9] Benoist, B., McLean, E., Cogswell, M. and Egli, I. (2008) Worldwide prevalence of anaemia 1993-2005: WHO Global Database on Anaemia. World Health Organization, Geneva.

[10] Department of Census and Statistics Sri Lanka (2009) Prevalence of Anaemia among Children and Women. Demographic and Health Survey 2006-2007. Health Sector Development Project, Ministry of Healthcare and Nutrition, Colombo.

[11] Jayatissa, R. and Hossaine, S.M.M. (2010) Nutrition and Food Security Assessment in Sri Lanka 2009. Medical Research Institute, Sri Lanka.

[12] Chathurani, U., Dharshika, I., Galgamuwa, D., Wickramasinghe, N.D., Agampodi, T.C. and Agampodi, S.B. (2012) Anaemia in Pregnancy in the District of Anuradhapura, Sri Lanka-Need for Updating Prevalence Data and Screening Strategies. Ceylon Medical Journal, 57, 101-106 https://doi.org/10.4038/cmj.v57i3.4148.

[13] Massawe, S., Urassa, E., Nyström, L. and Lindmark, G. (1999) Effectiveness of Primary Level Antenatal Care in Decreasing Anaemia at Term in Tanzania. Acta $O b-$ stetricia et Gynecologica Scandinavica, 78, 573-579.

[14] Ikeanyi, E.M. and Ibrahim, A.I. (2015) Does Antenatal Care Attendance Prevent Anaemia in Pregnancy at Term? Nigerian Journal of Clinical Practice, 18, 323-327. https://doi.org/10.4103/1119-3077.151730

[15] Mirzaie, F., Eftekhari, N., Goldozeian, S. and Mahdavinia, J. (2010) Prevalence of Anaemia Risk Factors in Pregnant Women in Kerman, Iran. Iranian Journal of Reproductive BioMedicine, 8, 66-69.

[16] Dim, C.C. and Onah, H.E. (2007) The Prevalence of Anaemia among Pregnant Women at Booking in Enugu, South Eastern Nigeria. Medscape General Medicine, 9, 11.

[17] Baig-Ansari, N., Badruddin, S.H., Karmaliani, R., Harris, H., Jehan, I., Pasha, O., Moss, N., McClure, E.M. and Goldenberg, R.L. (2008) Anaemia Prevalence and Risk Factors in Pregnant Women in an Urban Area of Pakistan. Food and Nutrition Bulletin, 29, 132-139. https://doi.org/10.1177/156482650802900207

[18] Pasricha, S.R., Caruana, S.R., Phuc, T.Q., Casey, G.J., Jolley, D., Kingsland, S., Tien, N.T., MacGregor, L., Montresor, A. and Biggs, B.A. (2008) Anaemia, Iron Deficiency, Meat Consumption, and Hookworm Infection in Women of Reproductive Age in Northwest Vietnam. The American Journal of Tropical Medicine and Hygiene, 78, 375-381. https://doi.org/10.4269/ajtmh.2008.78.375

[19] Wolmarans, P., Dhansay, M.A., Mansvelt, E.P., Laubscher, J.A. and Benade, A.J.S. (2003) Iron Status of South African Women Working in a Fruit-Packing Factory. Public Health Nutrition, 6, 439-445. https://doi.org/10.1079/PHN2003460

[20] Mennen, L., Hirvonen, T., Arnault, N., Bertrais, S., Galan, P. and Hercberg, S. (2007) Consumption of Black, Green and Herbal Tea and Iron Status in French Adults. European Journal of Clinical Nutrition, 61, 1174-1179.

https://doi.org/10.1038/sj.ejcn.1602634

[21] Temme, E.H.M. and Van Hoydonck, P.G.A. (2002) Tea Consumption and Iron Status. European Journal of Clinical Nutrition, 56, 379-386. https://doi.org/10.1038/sj.ejcn.1601309

[22] Dangour, A.D., Hill, H.L. and Ismail, S.J. (2001) Haemoglobin Status of Adult Non-Pregnant Kazakh Women Living in Kzyl-Orda Region, Kazakhstan. European Journal of Clinical Nutrition, 55, 1068-1075. https://doi.org/10.1038/sj.ejcn.1601267

[23] Zijp, I.M., Korver, O. and Tijburg, L.B. (2000) Effect of Tea and Other Dietary Factors on Iron Absorption. Critical Reviews in Food Science and Nutrition, 40, 
371-398. https://doi.org/10.1080/10408690091189194

[24] Speedyp, A.W. (2003) Global Production and Consumption of Animal Source Foods. The Journal of Nutrition, 133, 4048S-4053S.

https://doi.org/10.1093/jn/133.11.4048S

[25] Prathapan, S., Lindmark, G., Fonseka, P., et al. (2011) How Good Is the Quality of Antenatal Care in the Colombo District of Sri Lanka in Diagnosing and Treating Anaemia? Quality in Primary Care, 19, 245-250.

[26] Senadheera, D., Goonewardene, M. and Mampitiya, I. (2017) Anaemia and Iron Deficiency in Pregnant Women Attending an Antenatal Clinic in a Teaching Hospital in Southern Sri Lanka. Ceylon Journal of Medical Science, 62, 175-183.

https://doi.org/10.4038/cmj.v62i3.8521 